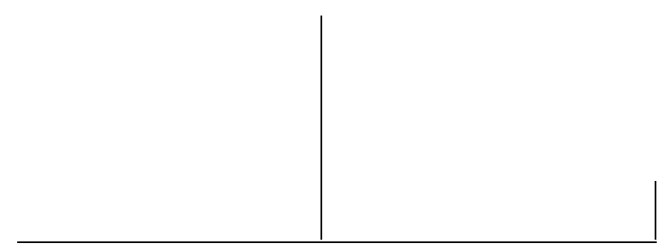

Rev. Latinoam. Psicopat. Fund., VI, 1, 13-25

\title{
A contribuição da Psicopatologia Fundamental para a Saúde Mental
}

Paulo Roberto Ceccarelli

O texto traz reflexões sobre a intersecção da psicopatologia fundamental com a saúde mental. Inicialmente, o autor apresenta uma breve digressão sobre as mudanças no conceito grego de pathos, desde sua origem até o seu uso mais comum: o sentido médico de doença. Discute-se também as origens da psicopatologia como disciplina organizada. Em seguida, apresentam-se os fundamentos histórico-teóricos da psicopatologia fundamental, suas concepções quanto à origem e à organização do aparelho psíquico e suas relações com as outras psicopatologias.

Finalmente, o autor discute a aplicabilidade dos princípios norteadores da psicopatologia fundamental às políticas de saúde mental.

Palavras-chave: Psicopatologia fundamental, pathos, saúde mental, cidadania 
Psicopatologia contém a palavra grega pathos. Embora em sua origem pathos possua vários significados, dois conceitos, bastante diferentes, interessam-nos sobremaneira: o passional, a paixão, a passividade; e o patológico, a doença, presente no diagnóstico médico. A fronteira que separa estas duas perspectivas é frágil e varia de acordo com as épocas e as civilizações (Cf. Martins, 1999).

O acometido pela paixão, o paciente, o passivo, é aquele que padece de algo cuja causa ele desconhece e que o leva a reagir, na maioria das vezes, de forma imprevista. A paixão atesta sempre, para usar um jargão lacaniano, nossa permanente dependência ao Outro; um ser autárquico não teria paixões. Assim, só faz sentido falar de paixões onde houver imperfeição ontológica.

Duas grandes vertentes histórico-filosóficas, que antecedem a própria noção moral e jurídica de sujeito, tentarão explicitar o pathos, a paixão. A primeira, encabeçada por Aristóteles, entende a paixão como um elemento intrínseco ao ser humano que não deve ser nem extirpado nem condenado. A segunda vertente, derivada de Platão e do estoicismo, vê nas paixões um obstáculo, uma força que deve ser vencida.

Para Aristóteles, por não escolher suas paixões, o homem não é responsável por elas, mas sim pela influência delas nas suas ações. A partir daí, seria possível julgar o aspecto ético do sujeito. Tal juízo é feito devido à possibilidade das paixões serem dosadas: sem paixão não existe escala de valores éticos. A grande dificuldade, em Aristóteles, para determinar se houve desmedida, se a paixão foi além do que deveria, é que não há uma referência única que serviria para todos os homens: cada um alcança o equilíbrio que lhe é próprio dentro de sua história. Não se deve contar com uma lei moral que harmonize as paixões: “...em nome da lei só se pode reprimir” (Lebrun, 1991, p. 24). Ainda que, devido a particularidades da vida, o sujeito tenha vivido 


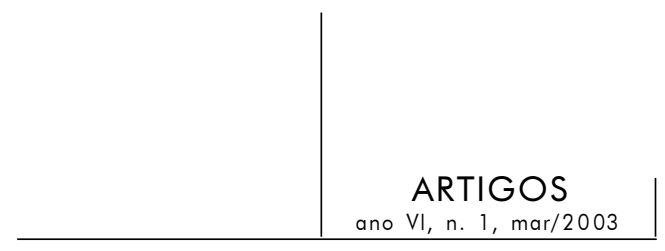

suas paixões de forma desenfreada, há momentos em que ele pode, por vontade própria, corrigir isso: para Aristóteles não há circunstâncias atenuantes. Mesmo não declarando guerra às paixões e propondo que se deva dominá-las e não reprimi-las, Aristóteles tem como inconcebível considerar involuntário um comportamento passional. Visto não ser possível renunciar às paixões, o homem virtuoso é, nesta perspectiva, aquele que aprimora a sua conduta para saber utilizar, nos seus atos, a medida exata de paixão; esta última deve estar a serviço do logos, do conhecimento, da razão. O homem virtuoso é, então, aquele que age em harmonia com suas paixões; que alcança o equilíbrio logos/paixão. Em suma: Aristóteles compreende a paixão como "uma tendência implantada na natureza humana, mas eminentemente suscetível a ser educada" (Ibid., p. 20). Cabe ainda lembrar que, para ele, a paixão não é algo que nos leva a praticar uma ação ruim malgrado nossa vontade: um "crime passional". Ao contrário, é ela que dá estilo, e até mesmo unidade, às nossas condutas; que rege as ações humanas constituindo, em certas circunstâncias, acontecimentos que suscitam nossa admiração como a paixão, o pathos, expresso no amor de Antígona por seu irmão: não há nenhuma conotação moral. "Nada de grande se fez sem paixão", escreve Hegel.

No estoicismo, em franca oposição com as teses aristotélicas, combate-se a idéia de que as paixões sejam dados da natureza humana, constituindo preciosos auxiliares da razão. As paixões são, antes, obstáculos ao logos devendo, portanto, ser domadas. Contrariamente às teses aristotélicas, não haveria como utilizar as paixões para o aprimoramento pessoal e nada pode ser feito para ajudar o apaixonado enquanto este estiver presa de seu pathos.

Estas duas posições, aqui resumidamente apresentadas, suscitam profundas e decisivas questões ético-ideológico-econômicas ligadas à noção de psicopatologia e, conseqüentemente, ao que entendemos por saúde mental e como abordar a questão.

Como vimos, temos, de um lado, Aristóteles para quem o sujeito deve dar conta de suas paixões; deve utilizá-las a favor do logos. De outro lado, temos o estoicismo que sustenta que os apaixonados, os que estão sob o efeito do pathos, são irresponsáveis pelo que fazem. O único expediente a tomar é evitar que a paixão se expresse: deve-se estar suficientemente treinado para não se deixar levar pelas armadilhas da paixão e ser tragado por ela. Não se trata, como em Aristóteles, de deixar que a paixão apareça para tê-la, de certa forma, como aliada, mas sim de cortá-la pela raiz.

O que está em jogo nestas duas posições, e que afeta tanto os que padecem de sofrimento mental quanto aqueles que se propõem cuidar dele, é a questão da responsabilidade: enquanto a posição aristotélica estende esta noção, a estóica a restringe. Se, para uma posição, deve-se entender o pathos para tirar proveito 


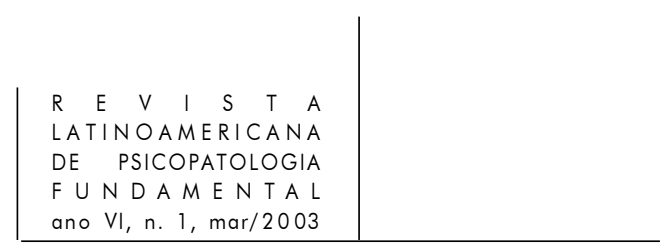

dele, na outra, ele deve ser destruído por tratar-se de uma doença. É nesta perspectiva que se defende que subjugado por uma paixão - o crime passional, por exemplo - a culpabilidade do sujeito fica reduzida. Já a posição aristotélica, que vê as paixões como constitutivas do ser humano e que defende a necessidade de integrá-las, sustenta que todo adulto normal deve ser responsável por suas paixões e arcar com as conseqüências de seu mau uso.

Avizinhamos aqui o interminável debate entre o normal e o patológico: ou consideramos o pathos como causa da conduta, como algo passível de ser modificado e sujeito a um julgamento ético, ou o consideramos como uma doença que aliena o sujeito transformando-o em objeto que necessita de cuidados especializados.

Além das inúmeras querelas - de ordem política, social, econômica, ideológica e tantas outras - que inflamam o debate acerca das políticas públicas de saúde mental, tal como aquela a que assistimos em torno da luta antimanicomial, estão presentes, mesmo que de forma latente, as duas posições em relação ao pathos. Um dos aspectos do problema - por exemplo, mantêm-se ou não os manicômios - é justamente a dificuldade de um consenso que determine de que maneira o portador de sofrimento mental deve ser tratado: ele é responsável ou não por seu pathos?

$\mathrm{Na}$ contemporaneidade, a linha que separa os dois conceitos de pathos - o passional e o patológico - tem se mostrado cada vez mais tênue. Observa-se um crescente deslocamento do domínio da ética para o da terapêutica. A partir do momento em que as raízes do comportamento do indivíduo encontram-se nas pulsões cuja origem ele ignora, a paixão passa a ser entendida como um estrangeiro-interno ${ }^{1}$ que, em vez de ser integrado à vida do sujeito - posição ética -, é submetido a um procedimento que visa exorcizá-la - posição terapêutica. Tratar as paixões significa, neste contexto, considerá-las patológicas, isto é, não mais entendê-las como parte do indivíduo com as quais ele tem que se haver, mas sim como algo perturbador que foge completamente a seu controle. O radical pathos, que quase invariavelmente envia à concepção médica de doença, é a expressão mais vulgar que ele adquiriu na concepção do homem comum. É interessante observar que a definição de "alienado" segue esta mesma linha. Segundo o Aurélio, o alienado, o louco, é aquele que, portador de uma perturbação mental, está incapacitado de agir segundo as normas legais e convencionais de seu meio social.

O indivíduo apaixonado não é mais culpabilizado, mas tratado como doente: cada vez mais a terapêutica ocupa o lugar da ética; o desvio, o lugar do erro; e

1. Sobre a questão do "estrangeiro-interno", ver CecCARelli, Paulo. R., Sexualidade e preconceito, 2000. 


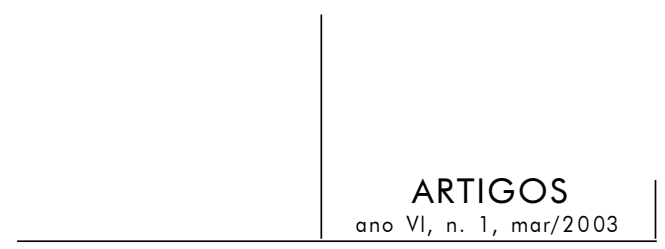

a cura, o do castigo. O que se depreende de tudo isso é que a exigência de normalidade é cada vez maior embora o delito não seja mais imputado a uma incapacidade de controlar as paixões, ao pathos/passional, mas, antes, a uma doença, ao pathos/patologia.

Evidentemente, o debate em torno da questão da responsabilidade, do delito, da possibilidade de se educar, ou não, as paixões, foi radicalmente transformado com o surgimento das diversas teorias que se propõem estudar o pathos. Particularmente, com a introdução da noção de inconsciente pela psicanálise, torna-se problemático manter tanto a posição de Aristóteles, que preconiza que se deve tirar proveito das paixões, quanto as posições estóicas, que dizem ser inútil qualquer tentativa de se trabalhar as paixões, já que é impossível dominá-las.

$\mathrm{O}$ aparecimento da psicopatologia como disciplina organizada, marcando ao mesmo tempo o rompimento com a psiquiatria do séc. XVIII, se dá com a publicação da Allgemaine Psychopathologie (Psicopatologia geral) de Karl Jaspers no início do século XX. ${ }^{2}$

Hoje, o termo "psicopatologia" encontra-se associado a um grande número de disciplinas que se interessam pelo sofrimento psíquico. Isso trouxe um problema tanto do diálogo intercientífico entre as diferentes abordagens epistemológicas de cada uma destas disciplinas, quanto da confrontação crítica dos modelos por elas utilizados, o que evidencia a irredutibilidade do fenômeno psíquico a uma única forma discursiva. A área da saúde mental, seja na clínica privada, nos hospitais ou nas instituições, é particularmente suscetível às conseqüências, por vezes catastróficas, do confronto das diferentes compreensões clínico-teóricas do pathos.

A tentativa mais conhecida para superar os impasses criados pela pluralidade de abordagens tem o seu expoente máximo no DSM-IV (Manual de Diagnóstico e Estatística da Associação Psiquiátrica Americana), que propõe oferecer uma definição empiro-pragmática das entidades nosográficas. ${ }^{3}$ Nele busca-se, acima de tudo, "o ideal de um acordo mínimo com relação à delimitação formal e operacional das categorias diagnósticas empregadas" (Costa Pereira, 1998, p. 62). Objetiva-se a criação de uma nomenclatura única que forneça uma linguagem comum a pesquisadores e clínicos de diferentes orientações teóricas. Esta mesma ideologia está presente no igualmente reputado CID-10 (Classificação Internacional

2. Segundo Fédida e Berlinck, a psicopatologia, como tradição, surge com os gregos encontrando sua expressão máxima no teatro de Ésquilo. Cf. Fédida, P., Tradition tragique du psychopathologique. A propos du pathei mathos de l'Agamemmon, 1992; BerLincK, M., O que é Psicopatologia Fundamental, 1998.

3. Para uma discussão crítica sobre o DSM-IV, ver Costa Pereira, M., Formulando uma psicopatologia fundamental, 1998. 


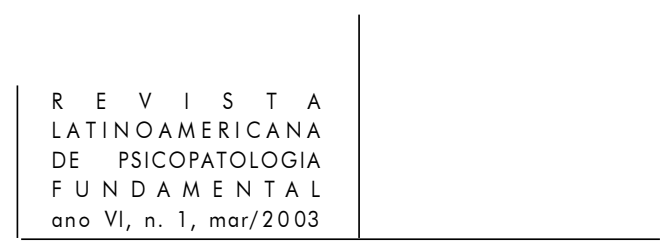

de Doenças). Na edição anterior, o CID-9, lê-se na Introdução: "Uma classificação deve ser antes de tudo um compromisso prático". Em suma, a abordagem empírico-pragmática das entidades psicopatológicas reivindica elaborar, unicamente a partir da observação direta dos fenômenos em questão, um sistema de classificação independente de qualquer a priori teórico. Isso significa deixar de lado os problemas etiológicos e centrar-se na nosografia. A grande crítica que se faz a esta abordagem é o fato de não levar em conta a subjetividade tanto daquele que está sendo "classificado" quanto daquele que classifica: o olhar de quem olha não é imune à sua própria organização subjetiva.

A isso vem juntar-se o desenvolvimento das neurociências e, sobretudo, o espantoso crescimento dos psicofármacos, que reforça a idéia da origem biológica dos transtornos psíquicos. Nesta perspectiva, não é exagerado supor que, num futuro não muito distante, poder-se-á tratar um determinado transtorno psíquico sem a ajuda da psicopatologia em suas múltiplas vertentes. Isto é, sem que seja necessário conhecer os aspectos subjetivos, os conflitos interiores e as experiências psíquicas do sujeito: bastará conhecer o uso das moléculas químicas (Ceccarelli, 2001).

\section{Psicopatologia fundamental}

É na pluralidade das psicopatologias que surge a Psicopatologia Fundamental, termo proposto em meados dos anos 1980 por Pierre Fédida (Berlinck, 1998), e que deu origem, na Universidade de Paris VII, ao Laboratoire de Psychopathologie Fondamentale et Psychanalyse. No Brasil, assim como em outros países, existem vários laboratórios que seguem está proposta de pesquisa.

A preocupação central da Psicopatologia fundamental é de contribuir para a redefinição do campo do psicopatológico, propondo uma reflexão crítica dos modelos existentes e uma discussão dos paradigmas que afetam nossos objetos de pesquisa, nossas teorias e práticas. Isso significa que a Psicopatologia fundamental reconhece e dialoga com as outras leituras presentes na polis psicopatológica.

$\mathrm{Na}$ atualidade, a noção de fundamental, ou melhor ainda de "fundamentalidade", deve ser compreendida como uma "intercientificidade dos objetos conceituais próprios para definir um campo que, doravante, não mais é delimitado por uma oposição em relação ao "normal"' (Fédida, 1998, p. 116). A psicopatologia fundamental é um projeto de natureza intercientífica onde a comparação epistemológica dos modelos teórico-clínicos e de seus funcionamentos propiciaria a ampliação do limite e da operacionalidade de cada 


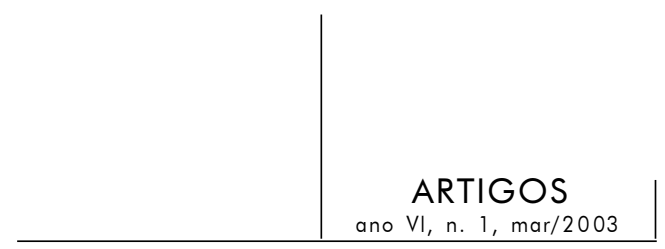

um destes modelos e, conseqüentemente, uma transformação destes últimos. Tal projeto levaria à construção de um espaço teórico-clínico, com fundamentos próprios, que permitiria a coexistência, o diálogo e o intercâmbio, dos diferentes modelos conceituais - neurociências, imunologia, farmacologia, oncologia e outros tantos - que lidam com o pathos.

Entretanto, é importante frisar que não se trata de uma interdisciplinaridade mas, antes, de uma transdisciplinaridade pois, campos diferentes, cada qual com métodos, procedimentos e objetivos que lhe são próprios não se comunicam facilmente. Para citar um exemplo dado por Fédida:

... uma pesquisa no domínio da neurobiologia sobre a doença de Parkinson, ou de Alzheimer, e aquilo que a psicanálise tem a dizer sobre o envelhecer, não entram diretamente em comunicação. O fato de que os neurobiólogos que trabalham com a questão do dormir e do sonhar parecem, às vezes, falar as mesmas coisas que os psicanalistas, não significam que estejam, de fato, falando das mesmas coisas. (Ceccarelli, 2001, p. 172)

A transdisciplinaridade reúne, em uma ampla rede de significações, os conhecimentos específicos e singulares de cada modelo em torno de uma concepção ética comum que "perpasse todos os saberes particulares e permita a abertura de um campo discursivo capaz de produzir interações, transportes e construções metafóricas" (Queiroz, 2000).

No epicentro da psicopatologia fundamental, cujo campo conceitual organiza-se em torno da referência psicanalítica, encontra-se o patei mathos esquileano: aquilo que o sofrimento ensina. Trata-se de resgatar o pathos, como paixão, e escutar o sujeito que traz uma voz única a respeito de seu pathos transformando aquilo que causa sofrimento em experiência, em ensinamento interno. Transformar o pathos em experiência significa, também, considerá-lo não apenas como um estado transitório mas, e talvez sobretudo, como "algo que alarga ou enriquece o pensamento" (Berlinck, 1998, p. 54). Cria-se, então, um discurso sobre as paixões, sobre a passividade, sobre o sofrimento, enfim, sobre o sujeito trágico. Encontramos aqui a essência de "Psicopatologia": o conhecimento, a razão - o logos - a respeito do pathos, da paixão, do sofrimento. O pathos, em si, nada ensina, não conduzindo senão à morte. Quando a experiência é, ao mesmo tempo, terapêutica e metapsicológica, estamos no âmbito da psicopatologia fundamental.

Abre-se, a partir daí, o campo transferencial onde um interlocutor, na posição de médico no sentido de Erixímaco: aquele que se ocupa dos fenômenos do pathos, traz para o sujeito a possibilidade de se pensar aquilo que, até então, nunca fora pensado. O médico - o psicopatólogo - no sentido dado por Platão em $O$ banquete, é aquele que tem a arte de se ocupar dos fenômenos do amor; 


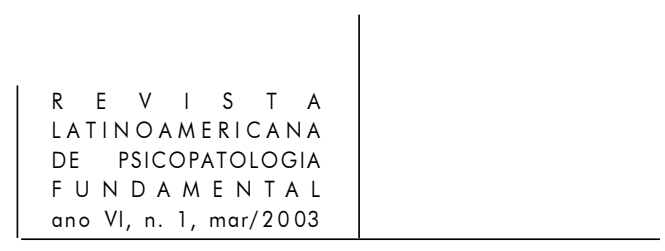

o que cuida de Eros doente pelo excesso de paixão; é aquele que, pela sua arte, restabelece o equilíbrio para que Eros seja liberado desse excesso. Tal como o espectador no teatro do tempo de Péricles, o psicopatólogo inclina-se sobre o paciente, escuta a singularidade que ali se manifesta, o que lhes confere - ao psicopatólogo e ao paciente - uma experiência única. Entretanto, é devido a esta experiência única e compartilhada, que a psicopatologia fundamental se distingue da psicopatologia geral: enquanto a última propõe um discurso classificatório sobre as doenças mentais, a primeira propõe um conhecimento do psiquismo através do pathos.

\section{Psicopatologia fundamental e aparelho psíquico}

Na perspectiva da psicopatologia fundamental, o aparelho psíquico é um prolongamento do sistema imunológico; uma organização que se desenvolveu a fim de proteger o ser humano contra os ataques, tanto internos quanto externos, que punham sua vida em perigo (Berlinck, 1999). Esta concepção está em filiação direta com as teses freudianas apresentadas em um de seus textos mais polêmicos, "Neuroses de transferência: uma síntese" (Freud, 1928). Neste texto, Freud concebe o aparelho psíquico (seelischer Apparat) como psicopatológico em sua origem: uma resposta defensiva à violência na qual o ser humano se viu exposto quando das mudanças provocadas pela chamada "era glacial". ${ }^{4}$ Esta catástrofe ecológica de proporções avassaladoras - ou, se preferirmos, esta perda do Éden - levou o ser humano a profundas reorganizações para enfrentar o excesso de violência tanto externas - as transformações do meio ambiente - quanto internas - as demandas pulsionais, o pathos - cujas satisfações se viram ameaçadas. Freud defende que a História da Humanidade - filogênese - é repetida a cada ser humano - ontogênese. É neste sentido que ele escreve que "as neuroses têm que prestar seu testemunho sobre a história do desenvolvimento da alma humana" (Freud, 1928, p. 72), o que equivale dizer que o ser humano traz um sofrimento psíquico, geneticamente herdado, causado pelo excesso. Com isso, Freud resgata a noção grega de pathos colocando-a como ingrediente central da essência do humano.

4. Hoje sabemos que não existe nenhuma relação entre a Era Glacial e o aparecimento do Homo Sapiens. Sobre este tema ver, por exemplo, EcclEs, J., Évolution du cerveau et création de la conscience, 1992; CAVAlli-Sforza, L. \& F., Qui sommes-nous?, 1997; Les origines de l'Homme, 2000; La langue d'Homo erectus, 2001. O que está em jogo na concepção freudiana é da ordem do mito, tal como o apresentado em "Totem e tabu". Trata-se de um episódio que mudou radicalmente a vida sobre o planeta. Neste sentido, é lícito dizer que houve uma "catástrofe". 


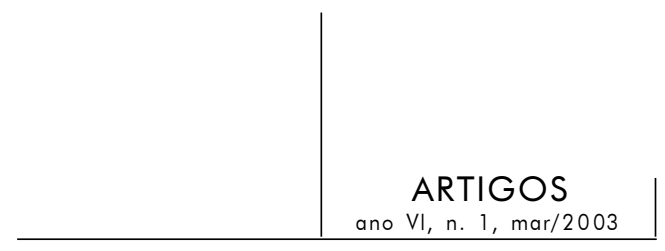

Freud inaugura um discurso sobre o pathos, uma psicopatologia, onde falar de normalidade, a não ser do ponto de vista estatístico, não faz mais sentido pois um tal estado sem tensão - o nirvana - só seria alcançado com a morte do organismo. Nesta perspectiva, as neuroses passam a ser compreendidas como criações que garantiriam a sobrevivência da espécie contribuindo, ao mesmo tempo, para a construção do psiquismo humano. Isto significa que, para Freud, em "Neuroses de transferência: uma síntese", as neuroses e as perversões são modos de subjetivação encontrados pelo sujeito. Por outro lado, aquele que não alcança a subjetividade, que não responde ao pathos com a sua "psicopatologia individual", é levado ao extermínio. Ou seja, como escrevi em outro lugar,

... o que a falta do Outro traz não é a morte biológica mas, antes, a morte ontológica que tem sua expressão máxima em algumas formas de psicose. A função essencial do Outro primordial, encarnada inicialmente pela mãe, é a de introduzir a criança no mundo da metáfora onde os objetos secundários substituem os primários. O narcisismo secundário, o do eu, só é alcançável pelo sacrifício do narcisismo primário. O bebê humano que recusa este imperativo seria impensável como humano, excluindo-se da cultura. (Ceccarelli, 2001b, p. 91-7)

A proposta da psicopatologia fundamental é pensar a questão páthica como dimensão inerente do Ser. Trata-se de "criar" uma psicopatologia própria para cada sujeito, que lhe permita transformar em experiência as manifestações de seu pathos.

É nesta perspectiva que defendo, em um trabalho anterior, que "as manifestações da sexualidade, tanto as 'normais' quanto aquelas que fogem à norma, devem ser compreendidas não como problemas mas, antes, como soluções" (Ceccarelli, 2000, p. 35). Este raciocínio, transportado para a psicopatologia fundamental, permite-nos pensar que a particularidade do trajeto identificatório de cada indivíduo é uma solução ou, se preferirmos, um sintoma, no sentido psicanalítico do termo: uma formação de compromisso frente às múltiplas variáveis com as quais o sujeito tem que lidar desde o seu nascimento. A palavra "solução" deve ser entendida no sentido matemático do termo: uma equação que comporta diferentes variantes frentes às quais, tal como em um sistema vetorial de forças, uma resultante, uma solução, será encontrada.

\section{Psicopatologia fundamental e saúde mental}

Até o final do século XIX não existia, a rigor, um saber sobre o sofrimento psíquico que acometia o homem. A preocupação vigente era sobre a doença, 


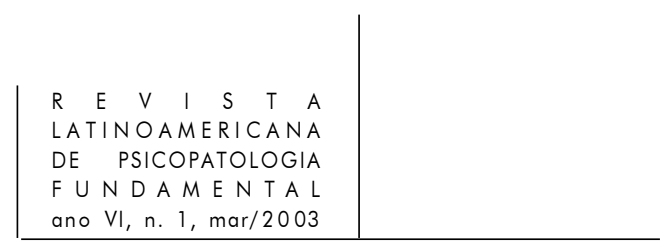

sobre a sintomatologia: conhecer para classificar. Em certa medida, o discurso psiquiátrico contemporâneo, que aparece na segunda metade do século XIX, guarda, em sua origem, esta mesma tradição. Os grandes psicopatólogos do século passado, dentre os quais Havellock-Ellis e Krafft-Ebing, tinham por preocupação classificar e etiquetar as organizações psíquicas que escapavam às referências de normalidade da época, o que aumentou consideravelmente a nosografia psiquiátrica. A psicopatologia geral de Jaspers continua, sob certos aspectos, esta mesma tradição ao deixar claro, já na Introdução, que seu objetivo é "o fenômeno psíquico realmente consciente". (Jaspers, s/d., p. 13)

Freud rompe com esta tradição psiquiátrica ao criar a situação psicanalítica onde "a alienação torna-se desalienante porque, no médico, ela se torna sujeito" (Foucault, 1978, p. 503). Com a introdução da dimensão do desejo, que submetido às leis da linguagem escapa a qualquer apreensão direta de sua finalidade, Freud postula que o sujeito - louco ou não - sempre que fala, fala do e a partir de seu pathos, que aqui confunde-se com a trama discursiva que o constitui. É esta trama, inicialmente encarnada pelo Outro, que possibilita que o pathos, como passividade, alienação, seja transformado, na situação terapêutica, em percepção, em experiência.

Respeitar o princípio da voz única, da singularidade do pathos que constitui 22 o sujeito que fala - proposta central da psicopatologia fundamental, como já foi dito -, é uma outra maneira de tratar a questão da cidadania.

No entanto, falar de cidadania só faz sentido onde existe um compromisso social não apenas por parte daqueles engajados de maneira mais próxima com as políticas de saúde mental, mas igualmente da sociedade como um todo. Este ponto toca uma questão crucial tanto para a implantação quanto para a continuidade de todo o processo: a disponibilidade de todos para rever arraigadas posições preconceituosas e estigmas seculares em relação ao portador de sofrimento mental. Ou, como bem o expressa Maria Elizabete Freitas (2000): "Que caminhos buscaremos para que a sociedade reconheça a necessidade de refletir sobre a cidadania do doente mental e a reestruturação da assistência em saúde mental?".

O respeito à singularidade tem, como contrapartida, que oferecer um tratamento mais "personalizado" onde as particularidades das subjetivações ganham contornos mais nítidos. Isto implica a criação de uma estrutura elaborada pela e para a comunidade, mas sobretudo a viabilização de "um espaço de convivência que acolhe, cuida e possibilita a utilização de diversos recursos, não se focalizando na doença, e enfatizando um projeto de Invenção Social”. (Ibid.)

Esta proposta de trabalho/pesquisa centrada na reflexão dos fundamentos dos modelos utilizados na escuta do paciente e em intervenções realistas pautase, antes de mais nada, em uma posição ética que "respeita o enraizamento 


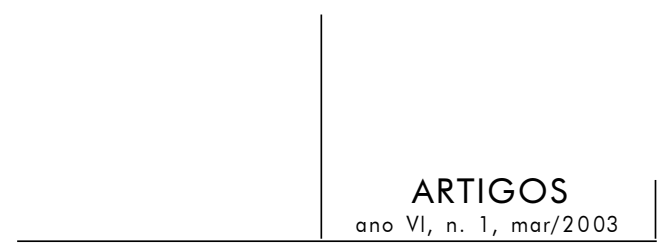

necessário de cada ser humano na realização de sua vida”. (Boff, 1999, p. 93) Trabalhar nesta perspectiva é reconhecer a particularidade psíquica, assim como a genética de cada um, e acreditar que o portador de um sofrimento psíquico possui um saber sobre o seu pathos.

Respeitar, ainda que na loucura, este "saber-sobre-si-mesmo" deve ser o ponto de partida para toda e qualquer discussão sobre as políticas de saúde mental. Embora uma nova perspectiva tenha estado presente na chamada Reforma Psiquiátrica que começou a estruturar-se no Brasil na década de $1980,{ }^{5}$ nunca é demais lembrar que não se trata apenas de melhorar a qualidade do atendimento ao usuário nas instituiçõos especializadas, mas sobretudo, de dar continuidade ao trabalho terapêutico além da crise que levou o sujeito a procurar a instituição; ou seja, reconhecer a todos o direito de cidadão: sem este reconhecimento, é o tecido social que se apresenta de forma perversa. ${ }^{6}$

Isso significa a implantação, ou implementação, de espaços de atendimento tanto institucionais quanto extra-institucionais cujos objetivos visariam, além do trabalho assistencial, profundas transformações na própria concepção de sofrimento psíquico.

Berlinck, M. O que é psicopatologia fundamental. Revista Latinoamericana de Psicopatologia Fundamental, São Paulo, v. I, n.3, p. 46-59, set./1998.

Catástrofe e representação. Notas para uma teoria geral da psicopatologia fundamental. Revista Latinoamericana de Psicopatologia Fundamental, São Paulo, v. II, n. 3, p. 9-34, set./1999, .

Boff, L. A águia e a galinha: uma metáfora da condição humana. 29. ed. Petrópolis: Vozes, 1999.

Bronz, A., Veloso, H., Delgado, S., Lanna, V., Oliveira, R., Acompanhamento Terapêutico: uma prática em construção. Campo da atenção psicossocial. Anais do primeiro Congresso de Saúde Mental de Rio de Janeiro. Rio de Janeiro: Tecorá 1997.

Carvalho-Freitas, M. E. Psicanálise, cidadania e as instituições de saúde mental. trabalho apresentado na Jornada de Psicanálise de Crianças e Adolescentes, Sociedade Psicanalítica da Paraíba, abril de 2000.

Cavalli-Sforza, L. \& F. Qui sommes-nous?. Paris: Flammarion, 1997.

5. Sobre a questão da Reforma Psiquiátrica, ver Bronz, A., Veloso, H., Delgado, S., Lanna, V., Oliveira, R., Acompanhamento Terapêutico: uma prática em construção, 1997, p. 15-20.

6. Sobre a questão do Social Perverso, ver Ceccarelli, P. R., Delinquiência: resposta a um social patológico, 2001a, p. 5-13. 


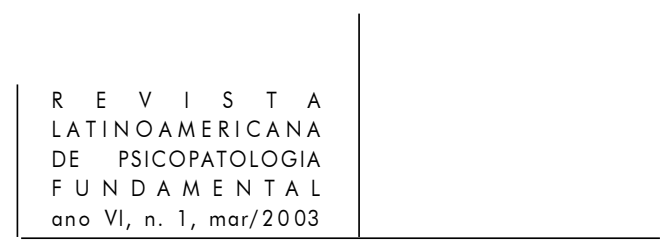

Les origines de l'Homme. Science et Avenir, Hors-Série, Avril/2000.

La langue d'Homo erectus. Science et Avenir, Hors-Série, janvier/2001.

Ceccarelli, P. R. Sexualidade e preconceito. Revista Latinoamericana de Psicopatologia Fundamental, São Paulo, v. III, n. 3, p. 18-37, set./2000.

Entrevista com Pierre Fédida. Revista Latinoamericana de Psicopatologia Fundamental, São Paulo, v. IV, n. 1, p. 168-74, mar./ 2001.

Delinqüência: resposta a um social patológico. Pulsional Revista de Psicanálise, São Paulo, ano XIV, n. 145, p. 5-13, maio/2001a.

A sedução do pai. Griphos. Pub. do Inst. de Est. Psican. - IEPSI-B.H., n. 18, p. 91-7. out./ 2001b.

Costa Pereira, M. Formulando uma psicopatologia fundamental. Revista Latinoamericana de Psicopatologia Fundamental, São Paulo, v. I, n. 3, p. 60-76, set./1998.

ECCLES, J. Évolution du cerveau et création de la conscience. Paris: Flammarion, 1992.

FÉdidA, P. Tradition tragique du psychopathologique. A propos du pathei mathos de l'Agamemmon. In: Crise e contre-transfert. Paris: PUF, 1992.

De uma psicopatologia geral a uma psicopatologia fundamental. Nota sobre a noção de paradigma. Revista Latinoamericana de Psicopatologia Fundamental, São Paulo, v. I, n. 3, p. 116, set./1998.

Foucault, M. História da loucura. São Paulo: Perspectiva, 1978.

FREUd, S. (1928). Neuroses de transferência: uma síntese. Rio de Janeiro: Imago, 1987. JASPERS, K. Psicopatologia geral. Rio de Janeiro: Atheneu, s/d. v. I.

Lebrun, G. O conceito de paixão. In: Os sentidos da paixão. São Paulo: Companhia das Letras, 1991.

Martins, F. O que é pathos. Revista Latinoamericana de Psicopatologia Fundamental, São Paulo, v. II, n. 4, p. 62-80, dez./1999.

QueIroz, E. O discurso perverso na clínica psicanalítica. Tese de doutorado em psicologia clínica, Laboratório de Psicopatologia Fundamental e Psicanálise, PUCSP, 2000

\section{Resumos}

El texto aporta reflexiones sobre la intersección de la psicopatología fundamental con la salud mental. Inicialmente el autor presenta una breve digresión sobre cambios del concepto griego de pathos, desde su origen hasta su uso más común: el sentido médico de enfermedad. Se discute también el origen de la psicopatología como disciplina organizada. En seguido, se presentan los fundamentos histórico-teóricos de la psicopatología fundamental, sus concepciones en cuanto al origen y la organización del aparato psíquico y sus relaciones con las otras psicopatologías. Finalmente el 


\section{ARTIGOS}

ano $\mathrm{VI}, \mathrm{n} .1, \mathrm{mar} / 2003$

autor discute la aplicabilidad de los principios que orientan la psicopatología fundamental a las políticas de salud mental.

Palabras clave:Psicopatología fundamental, pathos, salud mental, ciudadanía

Le texte présente quelques réflexions à propos de l'intersection de la psychopathologie fondamentale et la santé mentale. L'auteur commence par une petite digression à propos des changements du concept grec de Pathos dès son origine jusqu'au sens plus commun qu'il a pris de nos jours: le sens médicale de maladie. Il s'ensuit une discussion des origines de la psychopathologie en tant que discipline organisée, suivie par la présentation des fondements et historiques et théoriques de la psychopathologie fondamentale, de ses conceptions quant aux origines et à l'organisation de l'appareil psychique ainsi que ses relations avec d'autres psychopathologies.

Finalement, l'auteur discute la possibilité d'appliquer les principes de la psychopathologie fondamental aux politiques de santé mentale.

Mots clés: Psychopathologie fondamentale, pathos, santé mentale, citoyenneté

The text presents some considerations on the fundamental psychopathology and mental health intersection. The author begins by a small digression on the Greek concept of Pathos, starting from its very origins up to its most common meaning: the medical sense of disease. A discussion on the origins of psychopathology as an established discipline is then made followed by a presentation of the fundamental psychopathology historictheoretical background, its points of view on both the onset and the organization of the psychic mechanism as well as the relationships between fundamental psychopathology and other schools of psychopathologies.

Finally the author shows that the fundamental psychopathology main viewpoints are useful instruments to be used on public health politics.

Key words: Fundamental psychopathology, pathos, mental health, citizenship

Versão inicial recebida em junho de 2002

Aprovado para publicação em fevereiro de 2003 